\title{
The Effect of Emotional Intelligence of Operational Team Leaders on the Performance of Team Members
}

\author{
Moayyad Al-Fawaeer ${ }^{1}$ \& Ayman Wael Alkhatib ${ }^{1}$ \\ ${ }^{1}$ Al-Zaytoonah University of Jordan, Amman, Jordan \\ Correspondence: Moayyad Al-Fawaeer, Associate Professor, Business Administration Department, Faculty of \\ Business, Al-Zaytoonah University of Jordan, P.O. Box 130, Amman 11733, Jordan.
}

Received: June 21, 2020

Accepted: August 20, 2020

Online Published: September 5, 2020

doi:10.5430/rwe.v11n5p266

URL: https://doi.org/10.5430/rwe.v11n5p266

\begin{abstract}
This study is aimed at identifying the effect of emotional intelligence with its dimensions (self-awareness, self-regulation, empathy, motivation, and social skills) on the performance of working teams with its dimensions (task performance, contextual performance, and counterproductive performance) among employees on the operational lines of industrial companies operating in the Jordanian city of Sahab. The analysis is limited to employees in those companies, and the questionnaire is used as a data collection tool, taking a simple random sample to represent the study population. In addition to the analysis of 216 questionnaires, the SPSS program is used as a data analysis tool in the study. The study emphasizes the importance of emotional intelligence dimensions for operational team leaders, especially motivation and social skills dimensions because they have a higher effect on the task performance and contextual performance levels, while all dimensions of emotional intelligence have a negative effect on counterproductive performance for operational team members.
\end{abstract}

Keywords: emotional intelligence, operational teams, team performance, Jordan

\section{Introduction}

A changing business environment requires changing skills and knowledge that are quite different from those needed if working under a stable business environment; the key feature of today's business environment is that it is highly competitive with constant fluctuations in customer needs (Thomas, Roberts, Novicevic, Ammeter \& Loncar, 2018). This is why contemporary organizations have used working teams to meet the customers' requirements and to achieve outstanding performance to enhance their competitive position (Cullen, Edwards, Casper \& Gue, 2014; Gardner, Gino \& Staats, 2012; Gino, Argote, Miron-Spektor \& Todorova, 2010; Sony \& Mekoth, 2016). Working teams have been linked to positive outcomes such as productivity improvement, customer service, and quality, as well as innovation and consciousness in decision-making (Akgun, 2020; Gino et al., 2010; Goleman, Boyatzis \& McKee, 2013; Gully, Incalcaterra, Joshi \& Beaubien, 2002; Thomas et al., 2018; Wageman Gardner \& Mortensen, 2012). Emotional intelligence is one of the most important skills that working team leaders and employees should have to ensure survival and success in a changing, highly competitive business environment. Hence, emotional intelligence has been highlighted by many researchers as one of the main factors in the performance of employees and the importance of guiding it toward building positive trends in behavior and desired organizational outputs (Goleman et al., 2013; Sony \& Mekoth, 2016; Wong \& Low, 2002). Emotional intelligence is a prerequisite for skills leadership, staff development, and successful organization building through effective working team building. Employees who can manage their feelings can provide better performance than employees who are unable to do so. Mayer, Salovey, Caruso \& Sitarenios, (2001) showed that individuals with high emotional intelligence can better understand and perceive the feelings of coworkers and customers.

Emotional intelligence in the field of work, especially among employees on the operational lines, gives an individual the ability to deal with and adapt to different people. As a result, its absence leads to failure and creates negative and misguided reactions that reflect on the performance of the individual within the working team. The ability of team leaders to become self-realized and motivate their emotions helps the organization exploit unique opportunities, maintain creativity, avoid threats, and manage operational employees' dissatisfaction and solve problems (Zhang, Cao \& Wang, 2017). Emotional intelligence has become important in the management field as an indicator of successful job performance. It can increase as leaders' experience increases. Lack of emotional intelligence also 
exposes the working team leaders to various problems, including occupational compatibility, operational staff problems, and poor satisfaction with work. In organizations that select team leaders based purely on their mental capacities, the leaders are ultimately unsuccessful, demobilized, or forced to resign because of their inability to understand others and their weak social skills and self-control (Diefendorff, Croyle \& Gosserand, 2005; Goleman et al., 2013; Mayer et al., 2001; Shipley, Jackson \& Segrest, 2010). For many organizations, effectively studying frontline spanning and backline activities is a necessary prerequisite for successful product delivery and customer satisfaction (Gounaris, 2008). This cannot be achieved without emotional intelligence through training programs that will develop it.

Considering the lack of insights from previous literature about the effect of emotional intelligence of operational team leaders on the performance of employees in those teams, the aim of this study is to explore said effect and to identify the level of emotional intelligence in the operational team leaders. This study will be applied in the largest industrial city in Jordan, the Industrial City of Sahab, which is located in the Jordanian capital Amman, where there are 467 industrial companies that provide about 15675 job opportunities, with an investment volume of 1395 million Jordanian dinars, according to the report issued by the Jordanian Industrial Estates Company in early 2020. It is hoped that this study will contribute to detecting the importance of emotional intelligence among working team leaders on operational lines as well as the extent of emotional intelligence's contribution to improving the performance of operational employees. The importance of this study also lies in its being the first of its kind in the Jordanian business environment, one of the developing countries. Therefore, this study will provide conclusions and recommendations to factory managers that will increase the level of performance of employees and guide them toward positive behaviors in the performance of their tasks. The study will also contribute to highlighting the importance of emotional intelligence to upper and middle management for working team leaders so it can be taken into account in the selection and employment processes and in developing training programs that will instill it on the backlines of operations in factories.

\section{Literature Review and Hypotheses Development}

\subsection{Emotional Intelligence}

The need for emotional intelligence in contemporary business organizations has become an urgent necessity in that it helps employees become calm, focus on crises, and choose altruistic behavior aimed at achieving the organization's objectives. In this context, Goleman (2013) showed that emotional skill means an individual having the rare skill of being angry with the right person, at the right time, and for the right goal. Hence, emotional intelligence has gained the attention of researchers and academics in recent decades (Rosete \& Ciarrochi, 2005; Victoria, 2004), and these scholars have detected its importance in employee job satisfaction, organizational commitment, and good citizenship behavior. Emotional intelligence is also linked to the effectiveness of leadership. Sy, Tram \& O'hara (2006) studied the role of emotional intelligence in satisfaction and job performance, while Singh (2006) linked it to organizational learning and highlighted its role in contributing to innovation and implementing new processes. The role of emotional intelligence in leaders' job satisfaction has also been studied (Guleryuz, Guney, Aydin \& Asan, 2008, Sy et al., 2006). Leaders with high emotional intelligence tend to show emotions in the workplace by maintaining a positive mood when interacting with others (Asrar-ul-Haq, Anwar \& Hassan, 2017; Diefendorff et al., 2005; Liu \& Cho, 2018).

Therefore, emotional intelligence can be described as managing and modifying one's emotions to meet the regulations of the job and organization. Obradovic, Jovanovic, Petrovic, Mihic \& Mitrovic (2013) examined the relationship between the emotional intelligence of project managers and professional success. The mediating role of emotional intelligence in the relationship between work pressures and job performance (Yozgat, Yurtkoru \& Bilginoglu (2013) has also been examined. Salehi and Mohammed (2017) emphasized that managers in today's business environment must take into account the emotional intelligence of employees as a high-value resource and as a means of developing the organization's human resources to achieve its objectives. Many studies have also confirmed that emotional intelligence inputs affect the outcomes and outputs of the organization (Daus \& Ashkanasy, 2005; James, Hess \& Bacigalupo, 2011; Mayer, Salovey, \& Caruso, 2000). Mayer and Salovey (1997) added that social skills and decision-making skills are among the most prominent of these findings and outputs. Moreover, emotional intelligence improves group interaction among employees (Hwa \& Amin, 2016; Liu \& Cho, 2018).

Emotional intelligence perpetuates relationships among employees and facilitates knowledge sharing (James et al., 2011). A high level of emotional intelligence also increases employees' ability to focus on problem-solving, which in turn enhances their cognitive abilities. Researchers and academics have also found the importance of emotional intelligence in achieving effective performance, avoiding psychological stress, attaining job satisfaction, and 
reducing the employee turnover. It is also essential to understand the relationships in the field of work (Daus \& Ashkanasy, 2005; Salehi \& Mohammad, 2017). Therefore, organizations with a low level of emotional intelligence make employees afraid and anxious, and their performance may improve for a short period, but this will have negative consequences on their work output in the long term. Conversely, organizations with a high level of emotional intelligence will positively help employees to feel confident, they will exchange information more freely among themselves, and the business environment within the organization will become based on mutual trust among employees and management (Salehi \& Mohammad, 2017).

An individual employee with emotional intelligence will have an optimistic approach to life (Brinia, 2008). Likewise, employees' way of thinking and behavior are influenced by their emotions. Employees with a positive mood are more creative and can solve problems more easily than their counterparts (Clarke, 2010; Rozlell \& Scrogins, 2010). Therefore, it is important to have in a parallel manner an internal work environment that supports technical skills and develops emotional intelligence skills (Güleryüz, Güney, Aydın \& Aşan, 2008). Liu and Cho (2018) showed that many studies have emphasized that emotional intelligence is more important than general intelligence in most managerial roles, especially leadership roles.

\subsection{Emotional Intelligence Dimensions}

Several models have addressed emotional intelligence, as shown in Table 1. Salovey and Mayer (1990) are the pioneers who laid the foundation for emotional intelligence. Goleman (1995) adopted Salovey and Mayer's model (1990) after adding cognitive abilities as well as the Bar-on model (1997), to which noncognitive abilities, as well as personal and social skills (Zhang et al., 2017), have been added. In this study the author adopted the Goleman model (1995) as a mixed model that combines mental capacities and personality traits, which will be addressed as follows:

\section{- Daniel Goleman's Emotional Intelligence Model}

Goleman was influenced by Salovey and Mayer's work and model of emotional intelligence and seemed to be influenced by their writings and findings in further research in the field, which has played a significant role in increasing public and private sector interest and drawing attention to the concept of emotional intelligence and its importance to managers succeeding in meeting the needs of employees within organizations as well as in meeting the requirements of the organization as a whole. Goleman identified the component elements of emotional intelligence in five dimensions:

1. Self-awareness: This is the ability of the individual to know and formulate his or her own emotions and feelings and to express them and the needs related to them. Self-awareness is the basis of self-confidence. The individual needs to know his or her strengths and weaknesses, and this knowledge is the basis of his or her decisions. Goleman believed that self-awareness may be the most important aspect of emotional intelligence because it allows us to practice self-control. Of course, the idea does not refer to the emotion being suppressed but rather to being aware of these feelings so that one can deal with and effectively adapt to the surroundings.

2. Self-regulation: This is the ability of the individual to know how to address the emotions that hurt and disturb him/her; this treatment is the basis of emotional intelligence.

3. Motivation: Seeking motivation is an aspect of emotional intelligence through which an individual can know his or her steps toward reaching his or her goals and gain the perseverance and enthusiasm to achieve success.

4. Empathy: This is the ability to understand others and the skill of dealing with them in their emotional reactions. The sympathetic person can read, understand, and communicate with others' feelings and emotions accurately from their voice or facial expressions and not necessarily what they say. S/he is also able to unite with them emotionally, to understand their feelings and emotions, to communicate with them, to live with their problems, and to solve them.

5. Social skills: One of the basic life skills that individuals must learn is the skill of the art of relationships, how to deal properly with others, and how to placate the soul in times of anger; that is, the ability to manage social relationships efficiently and to establish easy relationships with others. A person with high social skills can persuade others and has the ability to negotiate and settle disputes. S/he often has many friends; $\mathrm{s} / \mathrm{he}$ appreciates cooperation and teamwork and has a high level of professional success. 
Table 1. Models of emotional intelligence

Emotional intelligence dimensions

\begin{tabular}{lll}
\hline Model & Model concentration & The concept of emotional intelligence \\
\hline $\begin{array}{l}\text { Salovey \& } \\
\text { Mayer }\end{array}$ & Capacities & $\begin{array}{l}\text { The ability to know one's emotions } \\
\text { and perceive emotions in others } \\
\text { (1990) }\end{array}$ \\
& accurately, understand and employ \\
& them in thoughts and behaviors, and \\
& appraise and express them. It is also \\
& the ability to generate or access \\
& feelings and understand emotions and \\
& emotional knowledge and the ability \\
& to regulate emotions to promote \\
& emotional and intellectual growth.
\end{tabular}

Salovey \& Capacitie

Mayer
- Perceiving emotions: in oneself and others accurately

- Using emotions: to facilitate thinking

- Understanding emotions: emotional language and the signals conveyed by emotions

- Managing emotions: to attain specific goals

\begin{tabular}{lll}
\hline Bar-On & Mixed & A system of noncognitive abilities, \\
(1997) & (mental capacities and & $\begin{array}{l}\text { competencies, and skills that affect a } \\
\text { personality traits) }\end{array}$ \\
& $\begin{array}{l}\text { the demands and pressures of the } \\
\text { environment }\end{array}$
\end{tabular}

\begin{tabular}{ll}
\hline Goleman & Mixed \\
(1995) & $\begin{array}{l}\text { (mental capacities and } \\
\text { personality traits) }\end{array}$
\end{tabular}

The capacity for recognizing our own feelings and those of others, for motivating ourselves, and for managing emotions well in our relationships with others

An appropriate and successful response of an individual to a wide variety of emotional stimuli, which moves from within the self and the surrounding environment

- Intrapersonal functioning

- Interpersonal skills

- Adaptability

- Stress management

- General mood

- Self-awareness

- Self-regulation

- Empathy

- Motivation

- Social skills

\begin{tabular}{lll}
\hline Singh & Personality traits & An appropriate and successful \\
(2006) & response of an individual to a wide \\
& variety of emotional stimuli, which \\
& moves from within the self and the \\
& surrounding environment
\end{tabular}

- Emotional competency

- Emotional sensitivity

- Emotional maturity

Capacity models involve the use of intelligence to manage emotions and emphasize the importance of cognitive processes in understanding and regulating emotions. These models view emotional intelligence as a purely mental capacity that works through the interaction between the mental and emotional aspects of an individual. These models consider emotions to be an important source of information. Individuals differ among themselves in their ability to process information of an emotional nature. This model is focused on measuring emotional intelligence according to actual mental performance rather than personal traits that are self-reported or through observing behaviors by others, which is the same method used to measure mental and cognitive abilities (Murphy \& Tyler, 2008).

Mixed models consider that emotional intelligence combines capacities related to processing and organizing emotional information and personality traits such as motivation and optimism (Rajah, Song \& Arvey, 2011). It can be noted that the element of understanding, perceiving, and controlling emotions is a common factor in all models reviewed in Table 1 despite the different methodologies involved in measuring them. There is also compatibility among all models regarding some of these component elements. Awareness of and the skill of controlling emotions is an essential quality agreed upon by all models for considering the individual emotionally intelligent. Salovey and Mayer (1990) described the skill of controlling emotions and adaptability as understanding and managing emotions. Bar-On (1997) described it as interpersonal skills and adaptability. Goleman (1995) described it as self-awareness and self-regulation. Singh (2006) classified it as a synonym for emotional maturity. 


\subsection{Emotional Intelligence and Working Teams}

The complexity and evolution of work methods in organizations led to the adoption of the teamwork style. Work required skills and capacities that exceeded the individual's capabilities, which required the use of the mental and emotional skills and abilities of the team members. Druskat and Wolff (2001) emphasized that modern organizations have adopted a team-based approach to achieve their objectives, making it even more important to develop emotional intelligence among team leaders to make teams work better. The team approach requires setting standards that characterize the most successful teams. On the other hand, as Clarke (2010) assured, understanding the nature of teamwork and, most importantly, those factors that either provide or underpin team effectiveness should better assist us to meet these expected performance gains.

Operational team leaders can build emotional intelligence within the team. Taylor (2014) showed the importance of emotional intelligence in knowledge sharing and increasing innovation in the workplace. Team success depends on the extent of cooperation, participation, and commitment to achieving objectives both at the individual and group levels and outside the group (Clarke, 2010; Rozlell \& Scrogins, 2010). Emotional intelligence is an indication of identifying effective team leaders. The team's success depends on how well it manages and monitors its own and others' emotions and how well it can deal with the needs of others (Koman \& Wolff, 2008; Lama \& Higgins, 2013; Stubbs, 2005).

Amundson and Susan (2013) showed that a team leader with emotional intelligence positively influences the emotional abilities of the team members he leads, improving team performance. Emotional intelligence has a positive effect on the effectiveness of the working team. The level of emotional skills of team members is a critical factor in team performance (Koman \& Wolff, 2008). One of the critical factors with which a team leader can influence the performance of employees is his leadership pattern and thus the team's cohesion and confidence among its members (Goodwin \& Johnson, 2000; Koman \& Wolff, 2008; Telleria, Little \& Macbride, 2002). Moreover, individuals with strong emotional intelligence are able to recognize, understand, and interact with the emotions of coworkers, superiors, and customers (Asrar-ul-Haq et al., 2017).

The operational team leader's emotional intelligence makes him understand his emotional behavior more effectively so he can try to control and guide it toward more positive relationships based on the support of the team members. The emotional intelligence of a team supervisor increases his ability to read the feelings of others, which can influence, refine, and guide them (Akgun, 2020; Goleman et al., 2013; Wageman et al., 2012). It should be noted that the acquisition of emotional intelligence will not eliminate manifestations of anger, frustration, and indignation among employees. However, the team leader can, by developing and acquiring emotional intelligence skills, develop his ability to read anger and frustration on the faces and in the behaviors of employees and thus address them by creating a better working environment and establishing more positive relationships.

Druskat and Wolff (2001) emphasized that the management of emotions and knowledge are critical factors in the deployment of emotional intelligence in working teams. Emotional intelligence is the ability of team members to develop norms that include developing proactive behavior toward solving problems, nurturing understanding among members, creating a positive working environment, and building relationships with groups outside the organization. The outstanding performance of team leaders depends in large part on their sense of the employees. Thomas et al. (2018) emphasized that the availability of emotional intelligence among working team leaders increases their impact on team members as regards achieving goals. Thus, the main study hypothesis could be formulated as follows:

\section{Ho1: Emotional intelligence of operational team leaders affects team members' performance.}

Individuals' performance within working teams and groups is categorized into task performance, contextual performance, and counterproductive performance (Borman, Ilgen \& Klimoski, 2003; Geher, 2004; Rotundo \& Sakeet, 2002). The dimensions of working teams' performance will be addressed, and the sub-study hypotheses will be formulated as follows:

\subsubsection{Task Performance}

This is the behaviors that contribute to implementing essential processes in the organization such as direct production and service delivery, and it includes every performance that contributes directly or indirectly to the implementation of the organization processes (Borman et al., 2003). The importance of emotional intelligence among working team leaders is highlighted here because emotional intelligence contributes to transforming individuals' behavior from conflict and dispute during task implementation into a competitive environment. The use of emotional intelligence also motivates individuals to work in competition, which positively affects individuals' performance of their tasks. The first sub-hypothesis can be formulated as follows: 


\section{Ho1.1: Emotional intelligence of operational team leaders affects team members' performance of tasks.}

\subsubsection{Contextual Performance}

This refers to all behaviors that contribute to the formation of culture and an organizational environment among team members, which indirectly contribute to the transformation and handling of the organization's substantial processes (Geher, 2004). This performance is characterized by being mostly outside the scope of basic functional tasks. It depends on the context in which processes are being addressed, such as helping coworkers with a work-related problem, ensuring continuous enthusiasm and exerting additional effort at work, as well as moving toward volunteering to perform tasks outside the formal role of the job. The second sub-hypothesis can be formulated as follows:

\section{Ho1.2: Emotional intelligence of operational team leaders affects team members' contextual performance.}

\subsubsection{Counterproductive Performance}

This type of performance is a collision and counterproductivity (Geher, 2004). The individual is characterized by bad, negative behavior at work, which does not stop at arriving late or taking unwarranted absences but also encompasses deviation, aggression, and misuse of resources as well as violence and a desire for revenge. Felps, Mitchell \& Byington (2006) defined bad behavior as any behavior that has a detrimental effect on other team members and also on overall group performance. Jaikumar and Mendonca (2017) argued that a negative member can have damaging effects on group performance. Therefore, identifying the individual's negative behaviors will help identify different outcomes at the individual, group, and organization levels. Thus, emotional intelligence will contribute to addressing these negative behaviors. Accordingly, the third sub-hypothesis can be formulated as follows:

\section{Ho1.3: Emotional intelligence of operational team leaders affects team members' counterproductive performance.}

\section{The Study Methodology}

This study is focused on identifying the effect of emotional intelligence with its dimensions (self-awareness, self-regulation, empathy, motivation, and social skills) on the performance of working teams with its dimensions (task performance, contextual performance, and counterproductive performance). This study is based on the analytical descriptive approach. It consists of a set of variables: independent variables, namely emotional intelligence dimensions, and dependent variables, namely the working teams' performance.

\subsection{The Study Tool}

A questionnaire was developed based on the previous relevant literature. The studies of Day and Carrolls (2004) and Hwa and Amin (2016) were used to develop the paragraphs on the emotional intelligence dimension, and the Rotundo and Sakeet (2002) study was used to develop the items of the work teams' performance dimension. The items were translated into Arabic and then presented to a group of specialized academics. The questionnaire items were modified according to the amendments of the arbitrators. The questionnaire included three main sections. The first section consists of the study tool respondents' demographic data paragraphs. The second section consists of the paragraphs on the independent variable and its dimensions (emotional intelligence), and the third section consists of the paragraphs on the dependent variable and its dimensions (the working teams' performance). Thus, 300 questionnaires have been distributed to employees in Jordanian industrial companies, and 216 questionnaires have been recovered for a recovery rate of $72 \%$.

\subsection{Data Collection}

The study population consists of all employees on the operational lines in the Jordanian industrial companies operating in the industrial city of Sahab. The author adopted the working team leaders as a unit for analysis. A simple random sample of 216 questionnaires was used from the Jordanian industrial companies. Table 2 shows the demographic characteristics of the study sample individuals. 
Table 2. Demographic characteristics of the study sample individuals

\begin{tabular}{llcc}
\hline Characteristics & Category & Frequency & \\
\cline { 3 - 4 } & & Number & Percentage \\
\hline Gender & Male & 174 & $72.2 \%$ \\
& Female & 60 & $27.8 \%$ \\
Age & Less than 30 & 148 & $68.5 \%$ \\
& $30-40$ years old & 52 & $24.1 \%$ \\
\multirow{3}{*}{ Work } & 40 years and over & 16 & $7.4 \%$ \\
& Technical official & 130 & $60.2 \%$ \\
& Administrative official & 54 & $25 \%$ \\
\hline Total & Director / Head of department & 32 & $14.8 \%$ \\
\hline
\end{tabular}

\subsection{Validity and Reliability of the Questionnaire}

To ensure the reliability of the internal consistency of the questionnaire paragraphs, the value of the Alpha Cronbach Coefficient was calculated. The values must be greater than 0.60 (Sekaran \& Bougie, 2016). Already, all the values have been greater than 0.60 , and thus the internal consistency condition was met. Convergent validity of the questionnaire paragraphs was confirmed by factor analysis test. All values of factor loadings were greater than 0.70 , according to Hair, Hult, Ringle \& Sarstedt (2016).

It was ensured that the independent variables were free from the problem of multicollinearity, which is one of the most important conditions for conducting a multiple linear regression test, and it was confirmed that the study data followed the normal distribution by ensuring that the coefficient of skewness values ranged from $(+1)$ to $(-1)$, as shown in Table 4. Data were distributed naturally because the values were less than 1 , and independent variables did not have the problem of high correlations among them because the variance inflation factor (VIF) value was less than 10 (Hair et al., 2016).

Table 3. Validity and reliability of the questionnaire paragraphs

\begin{tabular}{cccc}
\hline Dimension & Paragraph & Factor loading & Alpha Cronbach \\
\hline \multirow{3}{*}{ Self-awareness } & SA1 & 0.836 & \\
& SA2 & 0.901 & 0.887 \\
& SA3 & 0.885 & \\
SA4 & ER1 & 0.835 & 0.865 \\
Self-regulation & ER2 & 0.851 & \\
& ER3 & 0.870 & \\
& ER4 & 0.774 & 0.848 \\
Empathy & EP1 & 0.889 & \\
& EP2 & 0.812 & \\
& EP3 & 0.895 & 0.862 \\
EP4 & MO1 & 0.798 & \\
\hline \multirow{2}{*}{ Social skills } & MO2 & 0.825 & \\
& MO3 & 0.873 & 0.932
\end{tabular}




\begin{tabular}{cccc} 
& SS4 & 0.889 & \\
& SS5 & 0.889 & \\
\hline \multirow{3}{*}{ Task performance } & TP1 & 0.912 & 0.909 \\
& TP2 & 0.927 & \\
& TP3 & 0.922 & 0.939 \\
Contextual performance & COP1 & 0.930 & \\
& COP2 & 0.946 & \\
& COP3 & 0.896 & 0.912 \\
Counterproductive & COP4 & 0.908 & \\
performance & CPP1 & 0.917 & \\
& CPP2 & 0.926 & \\
\hline \multirow{2}{*}{ CPP3 } & 0.924 &
\end{tabular}

Table 4. The VIF test and skewness coefficient

\begin{tabular}{|c|c|c|c|}
\hline Variable & VIF & Tolerance & Skewness coefficient \\
\hline Self-awareness & 4.056 & 0.247 & -0.582 \\
\hline Self-regulation & 2.839 & 0.352 & -0.148 \\
\hline Empathy & 1.796 & 0.557 & -0.350 \\
\hline Motivation & 3.981 & 0.251 & -0.515 \\
\hline Social skills & 3.936 & 0.254 & -0.582 \\
\hline Task performance & - & - & -0.737 \\
\hline Contextual performance & - & - & -0.631 \\
\hline $\begin{array}{c}\text { Counterproductive } \\
\text { performance }\end{array}$ & - & - & 0.644 \\
\hline
\end{tabular}

\subsection{Testing of the Study Hypotheses}

The First Main Hypothesis: There is no statistically significant effect of the dimensions of emotional intelligence (self-awareness, self-regulation, empathy, motivation, and social skills) on working teams' performance in Jordanian industrial companies.

To test the main study hypothesis from which the three sub-hypotheses are formulated, the multiple linear regression method is used as follows:

Table 5. Results of testing the first sub-study hypothesis

\begin{tabular}{|c|c|c|c|c|c|c|c|}
\hline Variable & $\begin{array}{l}\text { Coefficient of } \\
\text { correlation } \\
\text { (R) }\end{array}$ & $\begin{array}{l}\text { Coefficient of } \\
\text { determination } \\
\left(\mathrm{R}^{2}\right)\end{array}$ & $\mathrm{F}$ & Sig. level & Beta (B) & $\mathrm{T}$ & Sig. level \\
\hline Self-awareness & 0.913 & 0.833 & 209.319 & 0.000 & 0.182 & 2.937 & 0.004 \\
\hline Self-regulation & & & & & 0.017 & 0.357 & 0.721 \\
\hline Empathy & & & & & -0.09 & -2.260 & 0.025 \\
\hline Motivation & & & & & 0.272 & 4.517 & 0.000 \\
\hline Social skills & & & & & 0.602 & 10.419 & 0.000 \\
\hline
\end{tabular}

The results in Table 5 show a strong and positive relationship between the dimensions of emotional intelligence (self-awareness, self-regulation, empathy, motivation, and social skills) and task performance. The value of the coefficient of determination has been 0.833 , which means that $83.3 \%$ of the variance in the task performance is 
caused by the five dimensions of emotional intelligence. All relationships between the dimensions of emotional intelligence and task performance are positive except for empathy because the beta value is -0.09 . The dimensions (self-awareness, empathy, motivation, social skills) are statistically significant because the calculated $\mathrm{T}$ values are greater than 1.96, and the probability value of all these dimensions is less than the significance level at 0.05 because it is 0.004 for the dimension of self-awareness, 0.025 for empathy dimension, and 0.000 for the motivation and social skills dimensions. Therefore, the null hypothesis is rejected, and the alternative hypothesis is accepted as a result of the significance of these dimensions. Meanwhile, self-regulation had no statistically significant effect, with the probability value 0.721 being greater than the statistical significance level at 0.05 .

Table 6. Results of testing the second sub-study hypothesis

\begin{tabular}{llllrrrr}
\hline Variable & $\begin{array}{l}\text { Coefficient of } \\
\text { correlation } \\
(\mathrm{R})\end{array}$ & $\begin{array}{l}\text { Coefficient of } \\
\text { determination } \\
\left(\mathrm{R}^{2}\right)\end{array}$ & $\mathrm{F}$ & Sig. level & Beta (B) & $\mathrm{T}$ & Sig. level \\
\hline Self-awareness & 0.862 & 0.742 & 121.09 & 0.000 & 0.116 & 1.474 & 0.142 \\
\hline Self-regulation & & & & 0.101 & 1.669 & 0.097 \\
Empathy & & & & -0.06 & -1.161 & 0.247 \\
Motivation & & & & 0.299 & 3.933 & 0.000 \\
Social skills & & & & 0.515 & 7.064 & 0.000 \\
\hline *Dependent variable: contextual performance & & & & & \\
\hline
\end{tabular}

The results in Table 6 indicate testing the second sub-study hypothesis as the results show a strong relationship between the dimensions of emotional intelligence (self-awareness, self-regulation, empathy, motivation, and social skills) and contextual performance. The correlation coefficient is 0.862 , while the coefficient of determination is 0.742 , meaning that $74.2 \%$ of the variance in the contextual performance is caused by the five dimensions of emotional intelligence. The beta value for the motivation dimension is 0.299 , and for social skills it is 0.515 , which are statistically significant because the calculated $\mathrm{T}$ values of these two dimensions are greater than 1.96 , and their probability value is 0.000 , which is less than the significance level at 0.05 . Therefore, the null hypothesis is rejected, and the alternative hypothesis is accepted. Meanwhile, the self-awareness and self-regulation dimensions are not statistically significant, with the probability value of these two dimensions being greater than the statistical significance level at 0.05 , and thus the null hypothesis is accepted.

Table 7. Results of testing the third sub-study hypothesis

\begin{tabular}{|c|c|c|c|c|c|c|c|}
\hline Variable & $\begin{array}{l}\text { Coefficient of } \\
\text { correlation } \\
\text { (R) }\end{array}$ & $\begin{array}{l}\text { Coefficient of } \\
\text { determination } \\
\left(\mathrm{R}^{2}\right)\end{array}$ & $\mathrm{F}$ & Sig. level & Beta (B) & $\mathrm{T}$ & Sig. level \\
\hline Self-awareness & 0.829 & 0.688 & 92.586 & 0.000 & -0.009 & -0.107 & 0.915 \\
\hline Self-regulation & & & & & -0.05 & -0.797 & 0.426 \\
\hline Empathy & & & & & -0.02 & -0.359 & 0.720 \\
\hline Motivation & & & & & -0.215 & -2.504 & 0.013 \\
\hline Social skills & & & & & -0.656 & -7.964 & 0.000 \\
\hline
\end{tabular}

The results in Table 7 indicate that the relationship among all dimensions of emotional intelligence is negative with counterproductive performance, indicating that the greater the level of emotional intelligence at the managerial level in companies, the fewer employees will be directed toward counterproductive performance. The beta values for the motivation and social skills dimensions are statistically significant, so the null hypothesis is rejected and the alternative hypothesis is accepted for these two dimensions. As for the self-awareness, self-regulation, and empathy dimensions, the null hypothesis is accepted, and the alternative hypothesis is rejected. 


\section{Results and Discussion}

This study was aimed at identifying the effect of emotional intelligence with its dimensions (self-awareness, self-regulation, empathy, motivation, and social skills) on the performance of working teams with its dimensions (task performance, contextual performance, and counterproductive performance). The results of the study indicate that there is a statistically significant effect of empathy, motivation, and social skills on the task performance, indicating that the use of managers and officials in the industrial companies operating in Jordan of empathy with employees at work and increasing their motivation through financial and nonfinancial motives, as well as focusing on social skills, will lead to enhancing employees' performance of their tasks. The results of this study are in agreement with those of Amundson (2003), Goleman et al. (2002), Jaikumar and Mendonca (2017), Wageman (2012), and Wong and Law (2002), while the self-awareness and self-regulation dimensions have no statistically significant effect on task performance. The results also indicate a statistically significant effect of the motivation and social skills dimensions on the contextual performance, while the self-awareness, self-regulation, and motivation dimensions have no statistically significant effect on contextual performance according to the study tool respondents' opinion. Concerning the effect of the dimensions of emotional intelligence on counterproductive performance, all dimensions are in a negative relationship with the latter, which shows that emotional intelligence plays a role in mitigating counterproductive performance, potentially leading to problems in the functioning of organizations and companies and increasing unfair competition among employees. The motivation and social skills dimensions have a statistically significant role in mitigating the counterproductive performance.

\section{Conclusion}

In general, although the results of this study are important, some limitations accompanied it, including the following:

- The current study is limited to Jordanian industrial companies operating in the industrial city of Sahab.

- This study relied on cross-sectional data.

- Sampling and analysis units were also limited to operational team leaders, and thus their results cannot be generalized across all economic sectors.

The results of this study are consistent with what Amundson (2003), Goleman et al. (2002), Jaikumar and Mendonca (2017), Wageman (2012), and Wong and Law (2002) have stated. The benefit of emotional intelligence and the need to develop it can be summarized as follows: It is important to recognize that an operational team leader or a supervisor with a high level of emotional intelligence has a positive effect on the work environment, being a source of energy. His/her mood and nature pass unconsciously to those around him/her, which improves the performance of team members and increases their productivity. Meanwhile, the author recommends the importance of developing emotional intelligence and leadership sense, especially in light of the severe shortage in the Jordanian labor market, and in developing countries in general, of team leaders and administrators who combine efficiency with these kinds of intelligence and leadership capacities. Leaders with high emotional intelligence tend to show emotions in the workplace by maintaining a positive mood when interacting with others. Therefore, the researcher recommends that company management develops emotional intelligence among operational leaders through training and workshops. The scholar also recommends removing communication barriers between team members, recognizing achievement and rewards, providing conditions for teamwork to support the growth of emotional intelligence, and avoiding poor performance by the employees on the operational lines. This will improve their performance of tasks and contextual performance and eliminate counterproductive performance on the operational lines. The author also recommends conducting similar studies in other economic sectors and different work environments so as to compare the findings of this study with those of future studies. This researcher proposes longitudinal future studies because this study relied on cross-sectional data. Therefore, longitudinal research can be conducted to confirm these results and affirm causal inferences empirically.

\section{References}

Akgun, A. (2020) Team wisdom in software development projects and its impact on project performance. International Journal of Information Management, 50, 228-243.

Amundson, S. (2003). An Exploratory Study of Emotional Intelligence, Group Emotional Competence, and Effectiveness of Health Care and Human Service Teams. International Journal of Contemporary Hospitality Management, 12(4), 228-239. 
Arfara, C., \& Samanta, I. (2016). The impact of emotional intelligence on improving team-working: the case of public sector - Naational Centre for Public Administration and Local Government. Social and Behavioral Science, 230, 167-175.

Asrar-ul-Haq, M., Anwar, S., \& Hassan, M. (2017). Impact of emotional intelligence on teacher' s performance in higher education institutions of Pakistan. Future Business Journal, 3(2), 87-97.

Bar-On, R. (2010). Emotional intelligence: an integral part of positive psychology. South African Journal of Psychology, 40(1), 54-62.

Bar-On, R. (1997). The Emotional Quotient Inventory Technical Manual. Toronto, Malt-Health Systems.

Borman, W. C., Ilgen, D. R., \& Klimoski, R. J. (2003). Handbook of psychology: Industrial and organizational psychology, Vol. 12. John Wiley \& Sons Inc.

Brinia, V. (2008). Management and Emotional Intelligence. Athens: Stamoulis.

Clarke, N. (2010). Emotional intelligence abilities and their relationships with team process. Team Performance Management, 16(1\2), 6-32.

Cullen, K. L., Edwards, B. D., Casper, W. C., \& Gue, K. R. (2014). Employees' adaptability and perceptions of change-related uncertainty: Implications for perceived organizational support, job satisfaction, and performance. Journal of Business and Psychology, 29(2), 269-280.

Daus, C. S., \& Ashkanasy, N. M. (2005). The case for the ability-based model of emotional intelligence in organizational behavior. Journal of Organizational behavior, 26(4), 453-466.

Day, L., \& Carrolls, A. (2004). Using an ability-based measure of emotional intelligence to predict individual performance, group performance, and group citizenship behaviours. Personality and Individual Differences, $36(6), 144-1458$.

Diefendorff, J. M., Croyle, M. H., \& Gosserand, R. H. (2005). The dimensionality and antecedents of emotional labor strategies. Journal of Vocational Behavior, 66, 339-357.

Druskat, V. U., \& Wolff, S. B. (2001). Building the emotional intelligence of groups. Harvard Business Review, 79(3), 80-91.

Felps, W., Mitchell, T. R., \& Byington, E. (2006). How, when, and why bad apples spoil the barrel: Negative group members and dysfunctional groups. Research in organizational behavior, 27, 175-222.

Gardner, H. K., Gino, F., \& Staats, B. R. (2012). dynamically integrating knowledge in teams: transforming resources into performance. Academy of Management Journal, 55, 998-1022.

Geher. G. (2004). Measuring Emotional Intelligence. Nova Science Publishers, New York.

Gibson, C., Waller, M. J., Carpenter, M., \& conte, J. M. (2007). antecedents, consequences, and moderators of time perspective heterogeneity for knowledge management in mno teams. Journal of Organizational Behavior, 28, 1005-1034.

Gino, F., Argote, L., Miron-spektor, E., \& Todorova, G. (2010). First, get your feet wet: the effects of learning from direct and indirect experience on team creativity. Organizational Behavior and Human Decision Processes, 111, 93-101.

Goleman, D., Boyatzis, R., \& McKee, A. (2002). The emotional reality of teams. Journal of Organizational Excellence, 21(2), 55-65.

Goleman, D., Boyatzis, R., \& McKee, A. (2013). Primal Leadership: Unleashing the Power of Emotional Intelligence. Harvard Business Press, United States.

Goleman. D. (1995). Emotional Intelligence. New York, Bantan Books.

Goodwin, D., \& Johnson, S. (2000). Teamwork Training - an Innovative Use of Flight simulators. Industrial and Commercial Training, 32(4), 132-135.

Gounaris, S. (2008). The notion of internal market orientation and employee job satisfaction: some preliminary evidence. Journal of Services Marketing, 22(1), 68-90.

Güleryüz, G., Güney, S., Aydın, E. M., \& Aşan, Ö. (2008). The mediating effect of job satisfaction between emotional intelligence and organisational commitment of nurses: A questionnaire survey. International Journal of Nursing Studies, 45(11), 1625-1635. 
Gully, S. M., Incalcaterra, K. A., Joshi, A., \& Beaubien, J. M. (2002). a meta-analysis of team-efficacy, potency, and performance: interdependence and level of analysis as moderators of observed relationships. Journal of Applied Psychology, 87, 819-832.

Hair Jr, J. F., Hult, G. T. M., Ringle, C., \& Sarstedt, M. (2016). A primer on partial least squares structural equation modeling (PLS-SEM). Sage Publications.

Hwa, M. A. C., \& Amin, H. (2016). Why emotion at work matters: examining the influence of emotional labour and emotional intelligence on workplace behaviours among service workers in east Malaysia. Kajian Malaysia, 34(1), 79-105.

Jaikumar, S., \& Mendonca, A. (2017). Groups and teams: a review of bad apple behavior. Team Performance Management: An International Journal, 23(5/6), 243-259.

James, D., Hess, A., \& Bacigalupo, C. (2011), Enhancing decisions and decision-making processes through the application of emotional intelligence skills. Management Decision, 49(5), 710-721.

Koman, E., \& Wolff, S. (2008). Emotional Intelligence Competencies in the Team and Team Leader: A Multi-Level Examination of the Impact of Emotional Intelligence on Team Performance. Journal of Management Development, 27(1), 55-75.

Lama, C., \& Higgins, E. (2013). Emotional Intelligence and Leadership Styles in China. Asia Pacific Management Review, 18(4), 441-467.

Liu, J., \& Cho, S. (2018). Interaction effect of display rules and emotional intelligence on hotel managers' and non-managers' work engagement. International Journal of Contemporary Hospitality Management, 30(3), 1903-1919.

Mayer, J. D. Y., \& Salovey, P. (1997). What is emotional intelligence?. In P. Salovey, \& D. Sluyter (Eds.), Emotional Development and Emotional Intelligence: Implications for Educators. Basic Book, New York, NY.

Mayer, J. D., Salovey, P., \& Caruso, D. R. (2000). Models of emotional intelligence. In R. Sternberg (Ed.), Hand book of Intelligence. Cambridge University Press, Cambridge.

Mayer, J. D., Salovey, P., Caruso, D., \& Sitarenios, G. (2001). Emotional intelligence as a standard intelligence. Emotion, 1, 232-242.

Murphy, K., \& Tyler, T. (2008). Procedural justice and compliance behaviour: The mediating role of emotions. European Journal of Social Psychology, 38(4), 652-668.

Obradovic, V., Jovanovic, P., Petrovic, D., Mihic, M., \& Mitrovic, Z. (2013), Project managers' emotional intelligence - a Ticket to success. Procedia - Social and Behavioral Sciences, 74, 274-284.

Pearce, C. L., \& Ensley, M. D. (2004). A reciprocal and longitudinal investigation of the innovation process: the central role of shared vision in product and process innovation teams. Journal of Organizational Behavior, 25, 259-278.

Rajah, R., Song, Z., \& Arvey, R. D. (2011). Emotionality and leadership: Taking stock of the past decade of research. Leadership Quarterly, 22, 1107-1119.

Rosete, D., \& Ciarrochi, J. (2005). Emotional intelligence and its relationship to workplace performance outcomes of leadership effectiveness. Leadership \& Organization Development Journal, 26(5/6), 388-390.

Rotundo, M., \& Sackett, P. R. (2002). The relative importance of task, citizenship, and counterproductive performance to global ratings of job performance: A policy capturing approach. Journal of Applied Psychology, $87,66-88$.

Rozlell, J., \& Scroggins, A. (2010). How much is too much? The role of emotional intelligence in self-managed work team satisfaction and group processes. Team Performance Management, 16(112), 33-49.

Salehi, M., \& Mohammadi, N. (2017). The relationship between emotional intelligence, thinking style, and the quality of investors' decisions using the long-linear method. Qualitative Research in Financial Markets, 9(4), 325-336.

Salovey, P., \& Mayer, J. D. (1990). Emotional intelligence. Imagination, Cognition, and Personality, 9, 185-211.

Sekaran, U., \& Bougie, R. (2016). Research methods for business: A skill building approach. John Wiley \& Sons. 
Shipley, N. L., Jackson, M. J., \& Segrest, S. (2010). The effects of emotional intelligence, age, work experience, and academic performance.

Singh. D. (2006). Emotional Intelligence at Work, Response Books (3rd ed.). New Delhi.

Sony, M., \& Mekoth, N. (2016). The relationship between emotional intelligence, frontline employee adaptability, job satisfaction and job performance. Journal of Retailing and Consumer Services, 30, $20-32$.

Stubbs, E. (2005). Emotional Intelligence Competencies in the Team and Team Leader: A Multi-level Examination of the Impact of Emotional Intelligence on Group Performance. Ph.D Thesis, School of Graduate Studies, Case Western Reserve University, USA, 234.

Sy, T., Tram, S., \& O`hara, L. A. (2006). Relation of employee and manager emotional intelligence to job satisfaction and performance. Journal of Vocational Behavior, 68, 461-473.

Taylor, J. (2014). Perceived Creativity: The Role of Emotional Intelligence and Knowledge Sharing Behaviour. Journal of Information and Knowledge Management, 13(4), 1-12.

Telleria, K., Little, D., \& Macbride, J. (2002). Managing Processes Through Team work. Business Process Management Journal, 8(4), 338-350.

Thomas, C. H., Roberts, F., Novicevic, M. M., Ammeter, A. P., \& Loncar, D. (2018). Familiarity and Fluid Team Performance: Leadership and HRM Implications. Research in Personnel and Human Resources Management, 36, 163-196.

Wageman, R., Gardner, H., \& Mortensen, M. (2012). the changing ecology of teams: new directions for team's research. Journal of Organizational Behavior, 33, 301-315.

Wong, C. -S., \& Law, K. S. (2002). The effects of leader and follower emotional intelligence on performance and attitude: An exploratory study. The Leadership Quarterly, 13(3), 243-274.

Yozgat, U., Yurtkoru, S., \& Bilginoglu, U. (2013). Job stress and job performance among employees in public sector in Istanbul: examining the moderating role of emotional intelligence. Procedia - Social and Behavioral Sciences, 75, 518-524.

Zhang, L., Cao, T., \& Wang, Y. (2017). The mediation role of leadership styles in integrated project collaboration: An emotional intelligence perspective. International Journal of Project Management, 36(2), 317-330.

\section{Copyrights}

Copyright for this article is retained by the author(s), with first publication rights granted to the journal.

This is an open-access article distributed under the terms and conditions of the Creative Commons Attribution license (http://creativecommons.org/licenses/by/4.0/). 